\title{
ALGUNAS REFLEXIONES CRÍTICAS SOBRE LA CONFORMIDAD EN EL PROCESO PENAL
}

\section{SOME CRITICAL REFLECTIONS ON CONFORMITY IN THE CRIMINAL PROCESS}

\author{
ANTONIO MATEOS RODRÍGUEZ-ARIAS \\ Fiscalía provincial de Badajoz
}

Recibido: 08/06/2019 Aceptado: 18/09/2019

\section{RESUMEN}

Es un hecho que la figura de la conformidad se ha instalado con fuerza en nuestro proceso penal generando indudables ventajas, pero también dudas respecto a la posible vulneración de derechos como los del acusado a un juicio público con todas las garantías, a no confesarse culpable y a la presunción de inocencia, además de generar un desplazamiento del juez como eje básico del procedimiento en favor del ministerio fiscal. El presente trabajo aborda el sistema de conformidad, su plasmación en el derecho español y los problemas que conlleva, al tiempo que se formulan algunas propuestas de mejora.

Palabras clave: Principios de legalidad y oportunidad, conformidad, poderes del ministerio fiscal, derechos del acusado.

\section{ABSTRACT}

It is a fact that the figure of conformity has been installed with force in our criminal proceeding generating undoubted advantages, but also doubts regarding the possible rights violation such as the accused right to a public trial with all the guarantees, not to confess guilt and the presumption of innocence, as well as generating a displacement of the Judge as the basic axis of the procedure in 
favor of the Public Prosecutor. The present work deals the conformity system, its embodiment in Spanish law and the problems it entails, while at the same time formulating some proposals for improvement.

Keywords: Legality and opportunity principles, conformity, the public prosecutor powers, rights of the accused.

Sumario: 1. Introducción. 2. El principio de legalidad. 3. El principio de oportunidad: 3.1. Concepto y fundamento; 3.2. Sus manifestaciones en el proceso penal español. 4. La conformidad: 4.1. Concepto y naturaleza jurídica; 4.2. El procedimiento ordinario; 4.3. El procedimiento abreviado; 4.4. El procedimiento para el enjuiciamiento rápido de determinados delitos, 4.5. El procedimiento por aceptación de decreto; 4.6. El procedimiento ante el tribunal del jurado; 4.7. Las posibilidades de actuación del ministerio fiscal. 5. Juicio crítico.

\section{INTRODUCCIÓN}

El indudable éxito de la institución de la conformidad en España, que no es más que una manifestación del principio de oportunidad, no la más importante desde el punto de vista cualitativo, pero sí desde el cuantitativo, no se ha debido tanto a las previsiones legales como a la implicación de las partes para potenciarla. De hecho, no es exagerado afirmar que tal éxito $^{1}$, no solo ha superado las expectativas del legislador, sino que incluso ha desbordado sus propios límites normativos.

Respecto al ministerio fiscal, ha sido la propia Fiscalía General del Estado la que ha instado a los fiscales a indagar todas las vías posibles para lograr el acuerdo, así, la Circular 1/1989, elaborada con motivo de la aprobación del procedimiento abreviado por Ley Orgánica 7/1988, de 28 de diciembre, señaló que esta reforma de la Ley de Enjuiciamiento Criminal (LECrim) conllevaba “...un notable cambio en los modos de actuación del Ministerio Público, que por imperativo de la obligación impuesta en el artículo 781 de procurar la simplificación del procedimiento,

1 En el año 2018 más del $70 \%$ de las sentencias pronunciadas por los juzgados de lo penal lo fueron de conformidad, a las que hay que añadir las dictadas, también de conformidad, por los juzgados de instrucción de guardia y los juzgados de violencia sobre la mujer. 
deberá promover esas soluciones facilitadoras de la sentencia, no ciertamente apartándose de la legalidad, pero sí utilizando todos los márgenes de arbitrio legal para llegar a situaciones de consenso...”.

Las defensas también buscan con interés la conformidad, siendo escasas las ocasiones en que no exploran esta posibilidad. Y, por último, entre los jueces y tribunales, pese a que no pueden adoptar ningún papel activo en la negociación, siendo su única actuación la del control de la legalidad del acuerdo alcanzado, tampoco es infrecuente que adopten posiciones que tienden a favorecerlo. Esta situación supone dotar de mayor protagonismo al ministerio fiscal, que se nos presenta como auténtico dueño del proceso, frente al órgano de enjuiciamiento, que se limita a dictar sentencia respetando lo pactado y a vigilar la legalidad del proceso.

Es cierto que las conformidades han aportado importantes ventajas a nuestro sistema procesal penal, como la economía procesal, la potenciación de la justicia restaurativa y la rehabilitación del delincuente, pero también ha generado un claro desplazamiento del eje del proceso penal desde el juzgador hacia la parte acusadora, al tiempo que algunas prácticas suponen la puesta en peligro de los derechos constitucionales del acusado.

\section{EL PRINCIPIO DE LEGALIDAD}

Antes de referirnos al principio de oportunidad, es preciso hacerlo al de legalidad que inspira el proceso penal español, en virtud del cual de todo delito nace acción para el castigo del culpable (artículo 100 LECrim), por lo que los miembros del ministerio fiscal están obligados a ejercitar todas las acciones penales que consideren procedentes, haya o no acusador particular en las causas, menos aquellas que el Código Penal (CP) reserva exclusivamente a la querella privada (artículo 105. 1 LECrim).

Además, este principio de legalidad afecta especialmente al ministerio fiscal. Sin duda, todos los órganos constitucionales están vinculados 
por este principio, reconocido como uno de los valores superiores de nuestro ordenamiento jurídico en el artículo 1.1 de la Constitución (CE), el cual, añade el artículo $9 \mathrm{CE}$, vincula a los ciudadanos y a todos los poderes públicos. Esta declaración general de vinculación no es óbice para que el artículo 124. 2 CE haga una declaración expresa de la sujeción del fiscal al principio de legalidad, como si quisiera recalcarla y reforzarla ${ }^{2}$. Pero la Constitución no se conforma con esa declaración, sino que va más allá, y no solo somete al ministerio fiscal a la legalidad, sino que le impone uno de los cometidos constitucionales más relevantes, cual es la defensa de la misma. El párrafo $1^{\circ}$ del mismo artículo $124 \mathrm{CE}$, sin perjuicio de las funciones encomendadas a otros órganos, impone al ministerio fiscal la misión de "promover la acción de la justicia en defensa de la legalidad”, a lo que añade la defensa de los derechos de los ciudadanos y del interés público tutelado por la ley. Así pues, mientras para otros órganos la legalidad es un límite, para el ministerio fiscal, además de un límite, es un fin, un objetivo en sí mismo, que se le impone al más alto nivel, en la norma fundamental del ordenamiento jurídico ${ }^{3}$.

Lo anterior no es óbice para que se vaya abriendo paso la idea de que la vigencia del principio de legalidad no impide la introducción del de oportunidad, en su modalidad reglada y no discrecional ${ }^{4}$. A ello contribuye lo que se ha calificado como crisis del principio de legalidad. Ciertamente, la vigencia de este principio, en virtud del cual el fiscal, como titular de la acción penal, debe intervenir siempre que existan indicios de la comisión de un hecho delictivo, es un requisito para la salvaguarda del principio de igualdad ante la ley, ya que es la garantía de que todos los que transgredan la ley penal serán perseguidos y que ningún delito

\footnotetext{
2 El artículo 6 del Estatuto orgánico del ministerio fiscal, subraya también la sujeción a este principio: "Por el principio de legalidad el ministerio fiscal actuará con sujeción a la Constitución, a las leyes y demás normas que integran el ordenamiento jurídico vigente ..."

3 Vid. Antonio Mateos Rodríguez-Arias: "La autonomía del Ministerio Fiscal a la luz de la Constitución”, en Persuadir y razonar: estudios jurídicos en homenaje a José Manuel Maza Martín, coord. por Carlos Gómez-Jara Díez (Madrid: Aranzadi, 2018), 993-1015.

4 En tal sentido, Cándido Conde-Pumpido Ferreiro, "El principio de oportunidad reglada: su posible incorporación al sistema del proceso penal español", en La reforma del proceso penal (Madrid: Ministerio de Justicia, 1989), 287-308.
} 
permanecerá impune, lo que, al mismo tiempo, lo convierte en un requisito para que los ciudadanos confíen en sus instituciones, y de forma específica en su administración de justicia ${ }^{5}$. Nos obstante, ello no impide reconocer que nuestro sistema penal, fruto de la sobrecarga de trabajo, sufre una congestión que impide que se desarrolle en plazos razonables $y$, en numerosas ocasiones, caiga en dilaciones que afectan a los derechos de las partes, tanto víctimas como investigados ${ }^{6}$.

\section{EL PRINCIPIO DE OPORTUNIDAD}

\subsection{CONCEPTO Y FUNDAMENTO}

Siguiendo a Gimeno Sendra podemos entender el principio de oportunidad como "la facultad que el ordenamiento procesal confiere al ministerio fiscal para, no obstante, la sospecha de la comisión de un delito público, dejar de ejercitar la acción penal o solicitar de la autoridad judicial un sobreseimiento o una reducción sustancial de la pena a imponer al encausado en los casos expresamente previstos por la norma y siempre y cuando hayan de tutelarse intereses constitucionalmente protegidos".

Con esta definición nos situamos dentro del llamado principio de oportunidad tasado o reglado, frente al libre o discrecional, ya que se admite su aplicación solo en los casos expresamente previstos y fundado en un interés constitucionalmente protegido, que, para este autor son: la obtención de una mayor y mejor aplicación del ius puniendi, la pronta reparación de la víctima y la rehabilitación del encausado ${ }^{7}$.

\subsection{SUS MANIFESTACIONES EN EL PROCESO PENAL}

\section{El proceso penal de menores}

5 Vid. Miguel Ángel Lamadrid Luengas, El principio de oportunidad como una herramienta de política criminal (Barcelona: Universitat Pompeu Fabra, 2015), 45.

6 En tal sentido, Fernando Velásquez Velásquez, La justicia penal: legalidad y oportunidad (Valencia Tirant lo Blanch, 2018), 23.

7 Vicente Gimeno Sendra, "El principio de oportunidad y el Ministerio Fiscal", Diario La Ley 8.746 (2016): 3 . 
La Ley Orgánica 5/200o, de 12 de enero, de responsabilidad penal de los menores (LORPM) contiene dos manifestaciones del principio de oportunidad reglada, que tienen su razón de ser en el hecho de que el principio que inspira este procedimiento es siempre el interés del menor.

En primer lugar, el ministerio fiscal, que es el que ostenta la competencia para la instrucción del procedimiento (artículo 16. 1), y conforme a lo dispuesto en el artículo 18 LORPM, puede desistir de la incoación del expediente siempre que los hechos denunciados constituyan delitos leves o menos graves sin violencia o intimidación en las personas, y que el menor no haya cometido con anterioridad otros hechos de igual naturaleza. De acuerdo con la Circular 1/2011 de la Fiscalía General del Estado este desistimiento sólo debe ser aplicado a menores que hubieren cometido un delito aislado, de forma ocasional, y que no se encuentren en un proceso delincuencial, de manera que no debe aplicarse ante hechos que, por su propia naturaleza, evidencien desempeño de papeles o asunción de valores propios del mundo de la delincuencia.

En segundo lugar, el artículo 19 LORPM regula el sobreseimiento del expediente por conciliación o reparación entre el menor y la víctima, convirtiéndose en el único supuesto de regulación legal expresa de la mediación penal ${ }^{8}$. Este precepto recoge la posibilidad del desistimiento del ejercicio de la acción penal por parte del ministerio fiscal, siempre que el hecho consista en un delito leve o menos grave y concurra alguna de las circunstancias siguientes: a) que el menor haya conciliado con la víctima; b) que el menor se comprometa a reparar el daño causado a la víctima o perjudicado por el delito; c) que el menor se comprometa a cumplir la actividad educativa propuesta por el equipo técnico en su informe.

Así pues, este precepto, como especifica su apartado segundo, prevé que el menor y la víctima puedan llegar a dos tipos de acuerdos, bien la conciliación, que requiere que el menor reconozca el daño y se disculpe

8 Vid. Mar Jimeno Bulnes, “¿Mediación penal y/o justicia restaurativa? Una perspectiva europea y española”, Diario La Ley 8.624 (2015): 7. 
ante la víctima, bien el de reparación, cuando el menor asuma el compromiso con la víctima o perjudicado de realizar determinadas acciones en beneficio de aquél o de la comunidad. En ambos casos actúa como mediador el equipo técnico, cuyo papel para el éxito de la mediación resulta fundamental.

\section{El juicio por delitos leves}

En el proceso penal de adultos son tres las manifestaciones del principio de oportunidad, una afecta a los delitos leves, otra a los delincuentes arrepentidos, en el seno de los delitos contra la salud pública y de terrorismo, y, por último, la posibilidad de alcanzar una conformidad entre acusación y defensa.

En los juicios por delitos leves, la LO 1/2015, de 30 de marzo, de modificación del CP, introdujo de forma expresa el principio de oportunidad al establecer en el artículo 963. 1. $1^{\text {a }}$ LECrim que el juez de instrucción podrá acordar el sobreseimiento del procedimiento y el archivo de las diligencias seguidas por delito leve cuando lo solicite el ministerio fiscal y concurran las siguientes circunstancias: a) que el delito leve denunciado resulte de muy escasa gravedad a la vista de la naturaleza del hecho, sus circunstancias, y las personales del autor, y b) no exista un interés público relevante en la persecución del hecho. En los delitos leves patrimoniales, se entenderá que no existe interés público relevante en su persecución cuando se hubiere procedido a la reparación del daño y no exista denuncia del perjudicado ${ }^{9}$.

\footnotetext{
9 La Circular 1/2015 de la FGE ha establecido las siguientes pautas para los fiscales a la hora de aplicar este artículo.

En los delitos leves públicos patrimoniales y en los que por afectar a bienes jurídicos personales tienen una o varias víctimas individualizadas:

- El archivo por razones de oportunidad, sólo se solicitará si ninguna víctima denuncia o manifiesta un interés explícito en la persecución del hecho, salvo en aquellos casos en que su postura se pueda estimar infundada, irracional o arbitraria. La mera afirmación de "quedar enterado" del ofrecimiento de acciones no será impedimento para solicitar el archivo.

- Cuando la víctima manifieste en el atestado policial o en el juzgado su deseo de no ser citada a juicio o su voluntad de que el procedimiento no siga adelante, se interesará el archivo por motivos de oportunidad, salvo que subsista un interés público necesitado de tutela conforme a los criterios apuntados en esta Circular.
} 
Nos encontramos ante una manifestación del principio de oportunidad con todas sus consecuencias, ya que permite, pese a lo dispuesto en los artículos 100 y 105. 1 LECrim, la renuncia al ejercicio de la acción penal nacida de un delito, y, aunque se reserva al campo de los delitos leves, y aunque su aplicación práctica es escasa ya que los juzgados tienden a señalar la celebración del juicio sin explorar la posibilidad del sobreseimiento por razones de oportunidad, es sin duda un significativo paso dentro de nuestra ajada ley procesal, aunque solo sea por el hecho de que la exposición de motivos de la LO 1/2015 mencione expresamente la introducción del principio de oportunidad en los términos siguientes:

"Para estos casos se introduce, con una orientación que es habitual en el derecho comparado, un criterio de oportunidad que permitirá a los jueces, a petición del ministerio fiscal, valorada la escasa entidad del hecho y la falta de interés público, sobreseer estos procedimientos”.

\section{El delincuente arrepentido}

En segundo lugar, el Código Penal permite la imposición de la pena inferior en uno o dos grados en delitos contra salud pública (artículo 376. $1 \mathrm{CP}$ ) y delitos de terrorismo (artículo 579 bis. $3 \mathrm{CP}$ ) a los sujetos que hayan abandonado voluntariamente sus actividades delictivas y hayan

\footnotetext{
- No se solicitará el archivo por motivos de oportunidad en los procedimientos incoados por actos de violencia física y psíquica cometidos en el núcleo de convivencia familiar, salvo casos excepcionales. - No se solicitará el archivo por motivos de oportunidad de los procedimientos incoados por delitos leves de detención ilegal (artículo 163.4 CP), contra el patrimonio histórico (artículo $124 \mathrm{CP}$ ), de falsedad documental (artículos 397, 399 y 400 CP), contra la administración pública (art. 406 CP) y contra la administración de justicia (artículos 456.1.3, 456.2 y 470.3 CP), salvo casos excepcionales. Tampoco en los delitos leves patrimoniales previstos en los artículos 236, 246, 247, 254, 255 y $256 \mathrm{CP}$ cuando el valor del objeto, ventaja o provecho obtenido por el culpable haya rebasado los 400 euros, ni en los delitos de ocupación de inmueble, edificio o vivienda que no constituya morada del artículo 245.2 CP.

En los delitos leves que afectan al orden público o a los intereses generales, los fiscales, a efectos de decidir sobre el ejercicio de las facultades derivadas del principio de oportunidad, ponderarán los criterios establecidos en esta Circular, atendiendo especialmente a las circunstancias concurrentes en el autor del hecho, como su edad juvenil, ocasionalidad de la conducta, arrepentimiento mostrado o disposición a reparar el mal causado.

Los fiscales tendrán a la vista la hoja histórico penal del denunciado antes de emitir el informe de oportunidad.
} 
colaborado activamente con las autoridades para impedir la producción del delito o para la identificación o captura de otros responsables.

Se trata de dos supuestos de tipos privilegiados, no circunstancias atenuantes, que, como recuerda el Tribunal Supremo (SSTS 115/2014, de 25 de febrero y 541/2015, de 18 de septiembre), al analizar la previsión del artículo $376.1 \mathrm{CP}$, obedecen a razones de política criminal, orientadas a favorecer la lucha contra el tráfico de drogas, especialmente el ejecutado por delincuentes organizados, mediante una especie de arrepentimiento activo que, comenzando por el abandono voluntario de la actividad delictiva, continúe con la confesión de los hechos y finalice con una colaboración eficaz con las autoridades. En cualquier caso, se trata de previsiones que pueden resultar ineficaces, ya que solo tras el desarrollo completo del proceso penal y la sentencia firme se obtiene el beneficio, lo que genera el riesgo de que el inicialmente arrepentido no ratifique sus declaraciones en el juicio oral ${ }^{10}$.

\section{LA CONFORMIDAD}

Pese a todo lo anterior, es la conformidad, y su regulación en los procesos penales más recientes, lo que verdaderamente ha supuesto la irrupción del principio de oportunidad dentro nuestro proceso penal, ya que, si bien esta figura está prevista en el artículo 655 LECrim desde el año 1882, nada menos que hace 137 años, fue la aprobación del procedimiento abreviado con la reforma de la LECrim de 1988 lo que significó su implantación práctica.

\subsection{CONCEPTO Y NATURALEZA JURÍDICA}

Siguiendo a Gómez Colomer podemos definir la conformidad del acusado en el proceso penal como "una institución de naturaleza compleja, en virtud de la cual la parte pasiva, es decir, tanto el acusado como

10 En tal sentido, Gimeno Sendra, "El principio de oportunidad...", 4. 
su defensor técnico, aceptan con ciertos límites la pena solicitada por la acusación, o la más grave de las solicitadas, si hubiera varios acusadores, procediéndose a dictar sentencia inmediatamente, al hacerse innecesaria la vista" 11 .

En cuanto a su naturaleza jurídica, sin exponer las distintas concepciones doctrinales ${ }^{12}$, y siguiendo al mismo autor, afirmaremos que se trata de un acto dispositivo que trae causa del principio de oportunidad, y que tiene naturaleza material y procesal, ya que, por una parte, se fija la pena a imponer, y, por otra, se aceleran los trámites procedimentales, pasándose directamente a dictar sentencia. Se trata, en definitiva, de una renuncia por parte del acusado al ejercicio de sus derechos fundamentales a la presunción de inocencia, a no confesarse culpable y a un proceso con todas las garantías ${ }^{13}$.

La jurisprudencia del Tribunal Supremo, que, desde su sentencia de 17/06/1991 ha hecho referencia a las distintas concepciones doctrinales de la conformidad, la considera una transacción penal que no opera sobre el objeto del proceso, sino sobre el desarrollo del procedimiento, dado que el objeto del proceso penal es indisponible: "la conformidad constituye una clara consecuencia de la admisión del principio de oportunidad que podrá reportar al acusado sustanciales ventajas materiales derivadas de una transacción penal. Entendiéndose por ello que no debe hablarse de la existencia de un pacto subyacente entre las partes -dada la indisponibilidad del objeto del proceso penal- y lo que hay es una concurrencia de voluntades coincidentes. En definitiva, la conformidad no sería una institución que operase sobre el objeto del proceso, sino sobre el

11 José Luis Gómez Colomer, "La conformidad, institución clave y tradicional de la justicia negociada en España", Revue Internationale de Droit Pénal 83 (2012): 7.

12 Para un análisis de las posturas doctrinales, vid. Jacobo Vigil Levi, "La institución de la conformidad en el proceso penal español", diponible en www.julgar.pt/wp-content/uploads/2014/o7, 2 ss.

13 Para profundizar sobre esta idea, vid. Juan Córdoba Roda, "Las conformidades entre acusación y defensa en los procedimientos penales y el problema de la renuncia al derecho", Diario La Ley 7898 (2012). 
desarrollo del procedimiento, posibilitando obviar el trámite del juicio oral" (STS 422/2017, de 13 de junio, con cita de otras anteriores).

Veremos a continuación cómo regula la LECrim la conformidad en los distintos tipos de procedimientos penales: procedimiento ordinario, procedimiento abreviado, procedimiento para enjuiciamiento rápido de determinados delitos, proceso por aceptación de decreto y procedimiento ante el tribunal del jurado.

La mera enumeración de estos procedimientos da idea de la necesidad de simplificar la regulación contenida en la LECrim.

\subsection{EL PROCEDIMIENTO ORDINARIO}

En el procedimiento ordinario la conformidad puede tener lugar en dos momentos procesales: al elaborar la defensa su calificación provisional (artículo 655 LECrim) y en el juicio oral al comienzo del interrogatorio del procesado (artículo 688.2 LECrim).

Según el artículo 655 LECrim, si la pena pedida por las partes acusadoras fuese de carácter correccional, al evacuar la representación del procesado el traslado de calificación podrá manifestar su conformidad absoluta con aquella que más gravemente hubiere calificado y con la pena que se le pida; es además necesario que el letrado defensor exprese que no conceptúa necesaria la continuación del juicio y que lo ratifique el procesado, en cuyo caso el tribunal dictará sentencia según la calificación mutuamente aceptada.

Al comienzo de las sesiones del juicio oral, si la causa fuese por delito para cuyo castigo se solicite la imposición de pena correccional, preguntará el presidente a cada uno de los procesados si se confiesa reo del delito y responsable civilmente (artículo 688. 2 LECrim). Si el procesado o procesados contestasen afirmativamente, el presidente preguntará al defensor si considera necesaria la continuación del juicio oral, y si 
contestase negativamente, el tribunal procederá a dictar sentencia en los términos expresados en el artículo 655 (artículo 694 LECrim)

Teniendo en cuenta el límite penológico establecido en este artículo, esto es, que la pena sea de carácter correccional, es decir, no superior a seis años de prisión, la conformidad en la práctica ha desaparecido del procedimiento ordinario, ya que éste está reservado para el enjuiciamiento de los delitos castigados con pena privativa de libertad superior a nueves años, de manera que solo cabrá la conformidad en el caso de la petición de la acusación no supere los seis años de prisión como consecuencia de la rebaja de grado de la pena prevista en el Código Penal por tratarse de una delito en grado de tentativa, por tratarse de cómplices o encubridores y no autores, y por aplicación de las circunstancias atenuantes de la responsabilidad penal ${ }^{14}$.

\subsection{EL PROCEDIMIENTO ABREVIADO}

Frente a estas previsiones, en las cuales la conformidad se reduce a la adhesión del procesado a la petición punitiva de la acusación, la introducción del procedimiento abreviado, operada por Ley Orgánica 7/1988, de 28 de diciembre, cambió el marco jurídico de la conformidad pasando a ser el eje central de la misma la negociación entre acusación y defensa. Las conformidades se alcanzan tras un cambio de la acusación en sus peticiones iniciales, cambio que responde a una negociación previa entre las partes de naturaleza extraprocesal ${ }^{15}$, que, como recuerda el Tribunal Supremo, carece de toda relevancia procesal hasta que se plasman en el proceso con todas las garantías ${ }^{16}$.

14 Vid. José Martínez Jiménez, Derecho Procesal Penal (Madrid: Tecnos, 2015): 250.

15 Vigil Levi, "La institución de la conformidad ...", 7.

16 STS 1094/2002, de 14 de noviembre. “... estos acuerdos carecen de efectos para el tribunal hasta que, en su caso, se manifiesten ante él con todas las garantías (...) Hasta ese momento se trata de relaciones extraprocesales, debiendo atenerse acusación y defensa a sus manifestaciones y actuaciones en el proceso y no a lo que haya podido ocurrir fuera de él". 
En el procedimiento abreviado la LECrim prevé tres momentos procesales en que puede alcanzarse la conformidad: en fase de diligencias previas (artículo 779. 1. $5^{\mathrm{a}}$ ), en fase intermedia (artículo 784. 3) y en fase de juicio oral (artículo 787. 1).

Según el artículo 779. 1. $5^{\text {a }}$ LECrim, el juez de instrucción pueda adoptar la resolución de transformar el procedimiento abreviado en diligencias urgentes de juicio rápido, conforme a los artículos 800 y 801, para lo que se requiere que, tras haber reconocido los hechos el investigado, asistido de su abogado y a presencia judicial, hubiere mostrado además su conformidad con el escrito de acusación formulado por las partes acusadoras, y que se trate de delito castigado con pena de hasta tres años de prisión, multa de cualquier cuantía o pena de otra naturaleza de duración no superior a diez años. En este caso el procedimiento termina con sentencia dictada por el juez de instrucción, en trámite de conformidad, y con la rebaja de un tercio de las penas solicitadas.

El artículo 784. 3 LECrim, que regula la elaboración del escrito de la defensa, recoge la posibilidad de que ésta manifieste su conformidad con la acusación formulada, o con la que contenga pena de mayor gravedad si fueren varias las formuladas, siendo necesario que el escrito lo firme también el acusado. Esta conformidad podrá ser también prestada, en cualquier momento anterior a la celebración de las sesiones del juicio oral, con un nuevo escrito de calificación que conjuntamente firmen las partes acusadoras y el acusado y su defensa.

En tercer lugar, y ya en la fase de juicio oral, al inicio de las sesiones y antes de la práctica de las pruebas, el artículo 787 LECrim regula la conformidad del acusado, la cual no podrá referirse a hecho distinto ni contener calificación más grave que la del escrito de acusación anterior, requiere la presencia del acusado, quedando excluidos de la conformidad los juicios celebrados en ausencia de éste, y que la pena no exceda los seis años de prisión. 
Esta conformidad alcanzada al comienzo del juicio oral es, con gran diferencia, la más frecuente en nuestros tribunales reduciendo a las demás a la categoría de anecdóticas, excepto las que se alcanzan en los juicios rápidos, con lo cual se pierde el efecto benéfico de economía procesal que se atribuye a las conformidades, al tiempo que sufren algunos principios del proceso penal que pueden afectar a derechos básicos del acusado $^{17}$. Para evitar estos inconvenientes, el 1 de abril de 2009, se firmó un protocolo de actuación entre la Fiscalía General del Estado y el Consejo General de la Abogacía con el objetivo de potenciar las conformidades previas al juicio oral ${ }^{18}$.

Un aspecto clave para que la institución de la conformidad no vulnere principios básicos del proceso penal, como los derechos constitucionales a los cuales renuncia el acusado, e incluso el principio de legalidad, es el control judicial de la conformidad alcanzada por las partes ${ }^{19}$, control que está previsto en el artículo 787. 3 y 4 LECrim. Siguiendo a VIGIL LEVI podemos diferenciar entre el control del contenido del acuerdo y el control del consentimiento prestado ${ }^{20}$.

El control del contenido del acuerdo está regulado en el artículo 787. 3 LECrim, según el cual, si el juez considera que la calificación es incorrecta o la pena solicitada no procediere legalmente, requerirá a la parte para que manifieste si se ratifica o no en su calificación, y, en caso de ratificación, el juez ordenará la continuación del juicio ${ }^{21}$. De este

17 Vid. infra, V. Juicio crítico.

18 La Instrucción 2/2009 de la FGE, dictada en desarrollo de dicho Protocolo, señala como objetivo a conseguir "que el juicio oral previamente conformado se señale prescindiendo en principio de la citación de los testigos y peritos, y de todas aquellas otras actuaciones cuyo objeto sea preparar la práctica de la prueba (...); descargar al órgano judicial de una laboriosa y a veces complicada tarea, y sobre todo evitar a los ciudadanos afectados por el delito y a los profesionales colaboradores con la administración de justicia el inútil desplazamiento y la frustrante pérdida de tiempo que hoy por hoy suponen las conformidades al inicio del juicio".

19 Por todos, Córdoba Roda, "Las conformidades entre acusación y defensa ..."; Javier Hernández García, "Rapidez y reforma del proceso penal", Jueces para la Democracia, Información y Debate 44 (2002): 30.

20 Vigil Levi, "La institución de la conformidad ...”, 23 ss.

21 La STS 188/2015, de 9 de abril, recuerda la necesidad de proceder como señala este precepto para respetar uno de los principios que integran las garantías constitucionales del proceso penal, como es el de contradicción: “... si la Sala considera incorrecta la calificación formulada, no puede aceptar sin más la conformidad entre las partes, prescindiendo de la celebración del juicio, y modificar posteriormente 
precepto deriva que el juez puede controlar la calificación de los hechos y la procedencia de la pena, pero no los hechos aceptados por las partes, ya que no se ha practicado ninguna prueba y carece de elementos de juicio para valorarlos. Respecto a la pena, su control ha de limitarse a si es procedente, lo que implica el control de su legalidad, quedando fuera del control judicial el ámbito discrecional de la penalidad en el que se materializa su individualización ${ }^{22}$.

En cuanto al control del consentimiento prestado, el párrafo segundo del artículo 787 LECrim exige que el juzgador oiga al acusado "acerca de si su conformidad ha sido prestada libremente y con conocimiento de sus consecuencias”, añadiendo el párrafo $4^{\circ}$ que, tras informar al acusado de las consecuencias del acuerdo, le requerirá para que preste su conformidad, y, si pese a prestarla, el juez albergara dudas sobre si la conformidad ha sido prestada libremente, ordenará la continuación del juicio. Así pues, el legislador ha querido rodear la manifestación de voluntad del acusado de suficientes garantías, siendo preguntando en dos ocasiones acerca de su conformidad, de si conoce el alcance de la misma y si la presta libremente, y, aún en el caso de que su respuesta sea afirmativa, el juez podría ordenar la continuación del juicio cuando tenga dudas sobre estos extremos. No obstante, como se verá más adelante, y pese a estas garantías, es aquí donde radica uno de los principales motivos de preocupación respecto a la conformidad, pues no siempre es fácil garantizar que el acusado otorga su consentimiento con pleno conocimiento de lo que hace y libre de todo tipo de presión ${ }^{23}$.

\footnotetext{
dicha calificación en la sentencia, inaudita parte, sino que debe trasladar su discrepancia a la acusación para que esta pueda modificar su escrito de casación en términos tales que la calificación sea correcta. Y, en otro caso, deber ordenar la continuación del juicio".

22 En tal sentido, Antonio del Moral García, "La conformidad en el proceso penal, reflexiones al hilo de su regulación en el ordenamiento español", Revista Auctoritas Prudentium 8 (2008): 15, http://www.unis.edu.gt/ap/fetch/conformidad-proceso-penal.pdf.

23 Vid. infra, V. Juicio crítico.
} 
4.4. EL PROCEDIMIENTO PARA EL ENJUICIAMIENTO RÁPIDO DE DETERMINADOS DELITOS

El tercer procedimiento al que hay que hacer referencia es el llamado procedimiento para el enjuiciamiento rápido de determinados delitos, introducido en la LECrim por LO 8/2002, de 24 de octubre, dentro del cual el artículo 801 LECrim regula la llamada conformidad "premial", cuya principal característica es que en la sentencia dictada por el juez de guardia se impondrá la pena solicitada reducida en un tercio, aun cuando suponga la imposición de una pena inferior al límite mínimo previsto en el Código Penal.

Es el único supuesto en el que el beneficio que conlleva la conformidad para el acusado está expresamente previsto en la ley, con lo que supone de mejora de la seguridad jurídica de esta institución, y su importancia ha sido destacada por el Tribunal Supremo (SSTS 752/2014, de 11 de noviembre y 422/2017, de 13 de junio), al señalar que la reforma de la LECrim supuso una auténtica modificación por vía indirecta del Código Penal, al permitir a modo de atenuante privilegiada con una eficacia especial la reducción de un tercio de la pena a la fijada por la acusación, lo que determinó la necesidad de conferir al artículo 801 LECrim el rango de ley orgánica del que carecía el original proyecto legislativo.

Para que quepa la conformidad en este tipo de juicios es necesario que los hechos objeto de acusación hayan sido calificados como delito castigado con pena de hasta tres años de prisión, con pena de multa cualquiera sea su cuantía, o con otra pena de distinta naturaleza cuya duración no exceda de diez años, y que la pena solicita o la suma de las penas solicitadas no supere, reducida en un tercio, los dos años de prisión. De alcanzarse la conformidad será el juez de guardia el que, tras controlar que se ajusta a la ley en los términos del artículo 787 LECrim, dicte sentencia de conformidad, debiendo también pronunciarse, una vez que declare su firmeza, sobre la concesión del beneficio de suspensión de la pena privativa de libertad. 


\subsection{EL PROCESO POR ACEPTACIÓN DE DECRETO}

El novedoso proceso por aceptación de decreto, introducido en la LECrim por Ley 41/2015, de 5 de octubre, y desarrollado en los artículos 803 bis a) a bis i), contiene otra regulación de la conformidad, con la peculiaridad de que en este caso la conformidad es consustancial al proceso, de manera que, si no se alcanza el acuerdo, la causa se transformará en otro tipo de proceso. Para que pueda incoarse este proceso es necesario que el delito esté castigado con pena de multa o de trabajos en beneficio de la comunidad o con pena de prisión que no exceda de un año y que pueda ser suspendida de conformidad con el artículo $80 \mathrm{CP}$, con o sin privación del derecho a conducir vehículos y ciclomotores. El fiscal elaborará un decreto en el que propondrá la pena a imponer, que, de ser aceptado por el investigado devendrá en resolución judicial firme, en caso contrario, el ministerio fiscal no se encontrará vinculado por el contenido de su decreto y proseguirá la causa por el cauce que corresponda.

Se trata de una modalidad de muy escasa aplicación frente al exitoso juicio rápido, entre otras razones porque al acusado le resultará más conveniente acogerse a la conformidad del artículo 801 LECrim. que está premiada con una reducción de un tercio de la pena.

\subsection{EL PROCEDIMIENTO ANTE EL TRIBUNAL DEL JURADO}

Por último, hay que referirse a la posibilidad de conformidad en el procedimiento ante el tribunal del jurado, regulado por Ley Orgánica 5/95, de 22 de mayo, cuyo artículo 50. 1 prevé que se disolverá el jurado si las partes interesaren que se dicte sentencia de conformidad con el escrito de calificación que solicite pena de mayor gravedad, sin que la pena pueda exceder de seis años de privación de libertad, matizando el párrafo segundo que si el magistrado-presidente entendiese que el hecho no se ha perpetrado, o que no lo fue por el acusado, no disolverá el jurado y mandará continuar el juicio, lo cual supone una importante especialidad 
respecto al procedimiento abreviado y al juicio rápido, ya que permite al magistrado-presidente controlar los hechos aceptados por las partes, especialidad que se justifica en que en este procedimiento, al contrario que los otros, cuando se alcanza la conformidad y se disuelve el jurado ya se ha practicado la prueba, por lo que el magistrado-presidente sí tiene elementos de juicio que le permiten valorar el acuerdo alcanzado desde el punto de vista de los hechos.

No obstante, el Tribunal Supremo (STS 482/2012, de 5 de junio) ha matizado que la excepción del artículo 50. 3 LOTJ no permite que la no aceptación de la conformidad y la no disolución del jurado se justifique por el magistrado-presidente en la eventual evaluación diferente que podría hacer el jurado tras la prueba practicada, pues, “...en definitiva, no se trababa de efectuar una valoración subjetiva de los hechos, un juicio probabilístico de la prueba para rechazar la conformidad, sino de determinar si existían motivos para estimar, en este caso, que el hecho descrito en el escrito de conformidad no había sido perpetrado (...) y si de esos hechos aceptados no resultaba la concurrencia de una causa de exención o de preceptiva atenuación”.

\subsection{LAS POSIBILIDADES DE ACTUACIÓN DEL MINISTERIO FISCAL}

Desde hace algunos años las numerosas reformas que ha venido sufriendo la LECrim han supuesto un fortalecimiento del papel del ministerio fiscal dentro del proceso penal, que se manifiesta en distintos aspectos, como son la cada vez mayor implicación del fiscal en la investigación de los delitos, la potenciación del principio acusatorio, y, especialmente, la introducción del principio de oportunidad a través de la figura de las conformidades, lo que nos permite hablar del poder de disposición 
del ministerio fiscal sobre la pretensión penal, presentándose el fiscal como dueño del objeto procesal ${ }^{24}$.

La esencia de la conformidad es la plena aceptación por parte del acusado, sin pruebas ni debates, del escrito de acusación de mayor gravedad a cambio de una reducción de la pena. Para conseguir esa reducción, en un sistema procesal como el español fuertemente inspirado en el principio de legalidad, el fiscal, obviamente, no podrá omitir en su acusación hechos penalmente relevantes, ni sustituir los hechos probados por otros distintos, ni calificarlos contra ley, ni solicitar penas no previstas en el precepto penal, pero sí cuenta con numerosos mecanismos para buscar un acuerdo que haga innecesario el juicio oral ${ }^{25}$.

La primera y más lógica posibilidad es rebajar la pena inicialmente pedida dentro de los límites penológicos que recoge cada tipo penal que frecuentemente son muy amplios. Si ello no fuera suficiente, y manteniéndose dentro de la concreta figura delictiva, en ocasiones el Código Penal recoge figuras atenuadas cuya apreciación depende de la valoración del hecho, así, en el delito de lesiones del artículo $147 \mathrm{CP}$, el párrafo $2^{\mathrm{o}}$ permite disminuir la pena cuando el hecho sea de menor gravedad, atendidos el medio empleado o el resultado producido. En la misma línea, el artículo 242. $4 \mathrm{CP}$ posibilita rebajar la pena prevista para el delito de robo con violencia atendiendo a la menor entidad de la violencia o intimidación ejercidas y valorando las restantes circunstancias del hecho. Otro ejemplo lo constituye el delito de tráfico de drogas, dentro del cual el segundo párrafo del art. $368 \mathrm{CP}$ permite también disminuir la pena en atención a la escasa entidad del hecho y a las circunstancias personales del culpable.

Por último, si el tipo penal no contuviera ninguna figura atenuada y el mínimo del marco penal no fuera suficiente para conseguir la

24 Argumento recogido por Nicolás Cabezudo Rodríguez, "Hegemonía del Ministerio Fiscal, principio de oportunidad y justicia negociada: las claves del nuevo modelo procesal español", en Reflexiones sobre el nuevo proceso penal: Jornadas sobre el borrador del nuevo Código Procesal Penal, coord. por Cristina Ruiz López y Raquel López Jiménez (Valencia: Tirant lo Blanch, 2015), 836.

25 Vid. Vigil Levi, “La institución de la conformidad ...”, 6-7. 
conformidad del acusado el fiscal puede acudir a las circunstancias atenuantes de la responsabilidad criminal, especialmente aquellas que están vinculadas al reconocimiento de la participación en el delito y a la reparación del daño. Esta última está expresamente recogida en el n. ${ }^{0} 5$ del artículo $21 \mathrm{CP}$ y su aplicación en las conformidades no plantea mayores problemas; sin embargo, la atenuante de confesión, prevista en el $n .^{\circ}$ 4 del mismo precepto, exige que la confesión del culpable se produzca antes de conocer que el procedimiento judicial se dirige contra él, lo cual representa un límite temporal que hace casi imposible su aplicación al acusado que confiesa para acogerse a los beneficios de la conformidad, ante lo cual los jueces y tribunales, en ocasiones, la aplican como atenuante analógica cuando la confesión se produce durante la declaración del acusado en juicio oral, amparándose en el artículo 21. $7 \mathrm{CP}^{26}$.

Sin embargo, esta práctica no parece acertada, ya que obvia un requisito temporal expresamente impuesto por el legislador, por lo que tiene difícil encaje dentro de la figura de la analogía. Así se deduce de la jurisprudencia del Tribunal Supremo, que, en sus sentencias 505/2016, de 9 de junio y 643/2016, de 14 de julio, señala que la atenuante de análoga significación no puede alcanzar al supuesto en que falten los requisitos básicos para ser estimada una concreta atenuante, porque ello equivaldría a crear atenuantes incompletas o a permitir la infracción de la norma, si bien tampoco puede exigirse una similitud y una correspondencia absoluta entre la atenuante analógica y la que sirve de tipo, pues ello supondría hacer inoperante el humanitario y plausible propósito de la analogía. En concreto, respecto a la llamada atenuante de confesión tardía, la STS 784/2017, de 30 de noviembre (con cita de otras anteriores), afirma que es aplicable en todos aquellos supuestos en los que no concurra el elemento cronológico exigido en la expresa previsión atenuatoria, pero aparezca una actuación colaboradora del investigado que sea reflejo de la asunción de su responsabilidad y que facilite la depuración del reproche que legalmente merecen los hechos en los que participó,

26 En tal sentido, Vigil Levi, "La institución de la conformidad ...", 6-7. 
exigiéndose por ello, así como por razones pragmáticas de política criminal, que el comportamiento del encausado en el seno de la investigación -si bien de manera tardía- favorezca de forma eficaz al esclarecimiento de los hechos y de los responsables, denegándose cuando los datos aportados sean conocidos o evidentes para la investigación. Obviamente el reconocimiento de culpabilidad que tiene lugar en las conformidades no tiene encaje en estas exigencias jurisprudenciales.

Son estas manifestaciones del principio de oportunidad, y particularmente la institución de la conformidad, las que han fortalecido los poderes del ministerio fiscal, no siendo exagerado afirmar que en estos casos se produce un desplazamiento del eje central del proceso penal desde el juez o tribunal hacia la acusación ${ }^{27}$.

\section{JUICIO CRÍTICO}

El sistema de conformidades ha alcanzado tal nivel de éxito en nuestras salas de justicia que se ha situado en primera línea del enjuiciamiento penal, algo impensable hasta la aprobación del procedimiento abreviado en 1988 y del procedimiento para enjuiciamiento rápido de determinados delitos en 2002, aún más, posiblemente impensable para el propio legislador. $Y$ es que parece que todas las trabas puestas al principio de oportunidad, tanto desde el punto de vista doctrinal como legislativo, aun en su modalidad reglada o tasada, que es la admitida en países de nuestro entorno, se flexibilizan, o abiertamente desaparecen, ante una de sus manifestaciones más frecuentes, cuya inconcreta y asistemática regulación, unida a la clara apuesta de acusaciones, defensas y órganos jurisdiccionales, por la negociación como forma de poner término al proceso, está generando un porcentaje de conformidades que contrasta con principios como los de indisponibilidad del objeto del proceso, búsqueda

27 Para profundizar sobre esta idea, vid. Velásquez, La justicia penal..., $1527 \mathrm{ss.}$ 
de la verdad material ${ }^{28}$, oralidad, contradicción, inmediación y valoración de la prueba por el órgano jurisdiccional ${ }^{29}$, principios que siguen inspirando nuestro proceso penal.

Sin duda, la conformidad es una institución útil cuyos beneficios (economía procesal, rápida reparación de la víctima y resocialización del acusado a través de la asunción de su responsabilidad y de la consecución de una disminución de la intensidad punitiva), justifican su existencia, pero también entraña deficiencias incompatibles con el entusiasmo con que todas las partes intentan llegar a un acuerdo que evite el juicio oral.

Así, respecto al acusado, frente al pretendido beneficio antes señalado, puede ser víctima del propio sistema de conformidades, especialmente cuando ésta se usa con el principal fin de aliviar la carga de trabajo de los órganos de enjuiciamiento y del ministerio fiscal, de manera que llegan a ponerse en peligro sus derechos constitucionales a un juicio público con todas las garantías, con posibilidad de utilizar los medios de prueba pertinentes para su defensa, a no declarar contra sí mismo, a no confesarse culpable y a la presunción de inocencia (artículo 24, $2 \mathrm{CE}$ ), y ello pese a que el Tribunal Supremo (SSTS 291/2014, de 7 de abril, 73/2017, de 2 de febrero y 422/2017, de 13 de junio) se ha encargado de recalcar que la conformidad "no es un acto de prueba, sino un medio de poner fin al proceso", de manera que "la conformidad es un declaración de voluntad de la defensa, que no constituye confesión"30, confesión del acusado que, por otra parte, tanto el Tribunal Constitucional como el

28 El Tribunal Supremo (SSTS 778/2006, de 12 de julio, 260/2006, de 9 de marzo y 422/2017, de 13 de junio) hace hincapié en que, frente al proceso civil que se rige que por el principio dispositivo y de verdad formal, en el proceso penal prepondera el principio de legalidad y el de indisponibilidad del objeto del proceso, siendo la búsqueda de la verdad material a la que se orienta este proceso.

29 Significativa es la STS 8/2011, de 11 de febrero que se expresa en los siguientes términos: "Es lógico, pues, el recelo hacia una forma de administrar justicia que se rinde ante exigencias pragmáticas y que entroniza el principio del consenso, desplazando otras ideas clave como el principio de contradicción, con la consiguiente estructura dialogal del proceso penal, y la necesidad de que el reproche penal sea el resultado de una apreciación probatoria verificada por un órgano jurisdiccional que ha de valorar los elementos de cargo y de descargo ofrecidos por las partes."

30 Estas sentencias aclaran que "debe distinguirse entre una declaración detallada y minuciosa sobre los hechos, propia del interrogatorio del acusado practicado en el juicio oral, con la mera conformidad y el reconocimiento de los hechos respecto de la acusación contra él formulada”. 
Tribunal Supremo admiten que puede suponer por sí la destrucción de esta presunción ${ }^{31}$. O, aún peor, se puede llegar a condenar a un inocente, pues no es exagerado afirmar, y así lo demuestran estudios empíricos ${ }^{32}$, que buena parte de los acusados, incluso entre los que se consideran inocentes, están dispuestos a confesar su culpabilidad y alcanzar una conformidad para evitar los riesgos de sufrir una sentencia condenatoria más severa.

Además, este riesgo de quiebra del derecho del acusado a que se celebre el juicio y se practiquen todas las pruebas de cargo y descargo se ve incrementado por algunas actitudes que se dan en nuestra práctica procesal.

En primer lugar, no es infrecuente que los fiscales, como estrategia ante la más que segura negociación para la conformidad, en los escritos de acusación soliciten penas más elevadas de las que en realidad consideran procedentes, para poder rebajarlas en el caso de acuerdo, lo cual sitúa al acusado en posición favorable a la conformidad a la vista de la generosa rebaja que se le ofrece.

En segundo lugar, y relacionado con lo anterior, se penaliza a los acusados que no alcanzan la conformidad, ya que se mantienen las peticiones de penas elevadas frente a las rebajas de las que se benefician los que llegan a un acuerdo, sin que ello responda a las circunstancias personales del sujeto, sino exclusivamente al hecho de si ha existido o no conformidad.

El Tribunal Supremo admite que la negativa a la conformidad de un coacusado frente a la admisión de las imputaciones por parte de los demás sirva de motivación para fundamentar la distinta entidad de las penas impuestas a uno y a otros, si bien matizando que con ello “... no se

31 La STS 512/2017, de 5 de julio, con cita de las SSTC 86/95, 49/99, 161/99, 136/2000, 299/2000, 14/2001, 138/2001 y las SSTS 550/2001, 676/2001 y 998/2002, afirma que la confesión del imputado es apta para provocar el decaimiento de la presunción de inocencia cuando tal confesión se ha efectuado comprobadamente, con respeto a las garantías del proceso, y, por tanto, con independencia de los motivos internos que tuviera el confesante para tal proceder.

32 Una referencia a los mismos se encuentra en Velásquez, La justicia penal ..., 64. 
está penalizando la no conformidad, sino recompensando la conformidad de los coacusados que aceptaron sus responsabilidades" (STS 487/2007, de 29 de mayo). La STS 457/2013, de 30 de abril insiste en la necesidad de diferenciar entre atenuar la pena a quien se conforma y agravar la pena a quien no se ha conformado ${ }^{33}$. En realidad, dejando al margen el supuesto del artículo 801 LECrim., en el que el beneficio para el acusado está expresamente previsto en la ley, en el resto de casos depende de si en la diferencia de penalidad vemos una recompensa al acusado que reconoció su culpabilidad o una penalización a aquél que solo ejerció su derecho constitucional a no declarar contra sí mismo y a no confesarse culpable, práctica esta última que el Tribunal Constitucional (sentencias 75 y 76/2007, de 16 de abril) ha considerado constitucionalmente inadmisible, por lesiva para los citados derechos fundamentales.

Una manera de evitar esta problemática sería extender el sistema establecido para las conformidades en los juicios rápidos al resto de los procedimientos, esto es, que el beneficio de la reducción en la pena al acusado que reconoce su culpabilidad venga establecido en la propia ley y aplicado por el juez.

En tercer lugar, el control jurisdiccional del acuerdo previsto en la LECrim, raramente culmina con el rechazo de la conformidad por el órgano jurisdiccional, ello se debe, sin duda, a que no es fácil rechazar un acuerdo beneficioso para el acusado y al que éste, aunque no con la contundencia que fuera deseable, ha prestado su consentimiento, máxime

33 Fundamento de derecho décimo primero: "La rebaja de la pena cuando existe conformidad es algo aceptable. Es un factor de individualización penológica (...) Ahora bien, aunque la línea es muy tenue, por cuanto toda atenuante en cierta medida se convierte en una agravante (una "no-atenuante") para quien no se encuentra inmerso en el supuesto base de la atenuación, hay que diferenciar claramente entre lo que significa atenuar la pena a quien se conforma, o a quien confiesa los hechos; de lo que supondría agravar la pena a quien no se ha conformado, a quien no ha confesado los hechos sencillamente por hacer uso de sus derechos a un proceso con todas las garantías y a no autoincriminarse. Lo expuesto puede dar cierta impresión de juego de palabras que escapa al raciocinio. Pero no es así: es plausible una rebaja de pena a quien se declara culpable por lo que comporta, de asunción de responsabilidades, de primer paso para la rehabilitación; pero ha de repudiarse la agravación para quien no asume ese comportamiento procesal legítimamente. No atenuar la pena no es lo mismo que agravarla". 
desde la posición de imparcialidad que debe adoptar el juzgador ${ }^{34}$, pero también influye la actitud de los jueces y tribunales de beneficiar los acuerdos como mejor forma de terminar el proceso penal ${ }^{35}$.

En cuarto lugar, hay que hacer referencia a las llamadas "conformidades encubiertas", esto es, cuando la conformidad no es formal, sino oficiosa, de manera que se celebra el juicio, pero el fiscal anuncia modificación de sus conclusiones con reducción de la pena según lo pactado y todas las partes renuncian a las pruebas, excepto la confesión del acusado, mecanismo que se suele utilizar para alcanzar acuerdos por encima de las penas máximas legalmente previstas para la conformidad, y que han merecido en repetidas veces el rechazo del Tribunal Supremo, así la sentencia 291/2016, de 7 de abril, según la cual: "la conformidad no puede ser clandestina o fraudulenta, encubierta tras un supuesto juicio, puramente ficticio, vacío de contenido y que solo pretende eludir las limitaciones legales. Ha de ser transparente y legal, porque con independencia del criterio más o menos favorable que se sostenga respecto de los beneficios que puede aportar el principio de consenso aplicado al proceso penal, este objetivo no puede obtenerse a través de procedimientos imaginativos o voluntaristas, sino que exige en todo caso el estricto respeto de los cauces y limitaciones legales”. La STS 808/2016, de 27 de octubre, reitera la ilegalidad de este tipo de conformidades.

Por último, respecto a la crítica de que las conformidades suponen un excesivo fortalecimiento de los poderes del ministerio fiscal en detrimento de los órganos jurisdiccionales ${ }^{36}$, tiene su fundamento en el hecho de el control jurisdiccional es uno de los aspectos claramente mejorable de nuestro sistema de conformidades.

Sobre este punto se han apuntado interesantes propuestas tendentes, por una parte, a asegurar que la adopción de la conformidad no

34 En tal sentido, Vigil Levi, "La institución de la conformidad...", 28.

35 Argumento recogido por Juan Carlos, "El Plea Bargaining, o cómo pervertir la justicia penal a través de un sistema de conformidades low cost”, Revista Electrónica de Ciencia Penal y Criminología, 20, $\mathrm{n}^{0} 6$ (2018): 16. http://criminet.ugr.es/recpc/20/recpc20-o6.pdf..

36 Vid. Velásquez, La justicia penal..., 55. 
comprometa la imparcialidad del juzgador, y, por otra, que éste ejerza un mayor control sobre el acuerdo para garantizar su legalidad. Así, en primer lugar, la regulación contenida en el Anteproyecto de ley de enjuiciamiento criminal de 2011 que encomendaba el control de la conformidad a un órgano distinto al de enjuiciamiento, con lo cual se obtienen varios beneficios, se descontamina al juzgador y la decisión sobre la validez de la conformidad, y se evita la actitud de potenciarla por parte del primero37. En segundo lugar, se propone que el juez pueda controlar que los hechos aceptados por las partes cuentan con indicios suficientes que justifiquen que se declaren probados ${ }^{3}$. Y, en tercer lugar, y en la misma línea, que el juez pueda controlar la individualización de la pena y su proporcionalidad a la gravedad del hecho y reprochabilidad concreto del autor no limitándose a la legalidad de la misma39.

En definitiva, la mejora de la institución de la conformidad ha de pasar necesariamente por superar el criterio utilitarista del ahorro de trámites procesales que conlleva, viendo en ella una forma de terminación del proceso con reproche penal, pero sin contradicción entre las partes ni práctica de la prueba, lo que requiere, para garantizar los derechos del acusado, incrementar el control judicial del acuerdo, ejercitado por un órgano distinto del de enjuiciamiento, y establecer por ley los beneficios para el acusado que se conforma, imposibilitando así castigar al acusado que no lo hace.

\section{REFERENCIAS BIBLIOGRÁFICAS}

Cabezudo Rodríguez, Nicolás. "Hegemonía del Ministerio Fiscal, principio de oportunidad y justicia negociada: las claves del nuevo modelo

37 En tal sentido, Antonio del Moral García, "Otra vez sobre la conformidad y conformidades en el proceso penal", Fernando Herrero Tejedor Algar - Liber Amicorum, dir. por Antonio Del Moral García y Jaime Moreno Verdejo (Madrid: Colex, 2015): 503.

38 Vid. Moral García, "Otra vez sobre la conformidad...".

39 Vid. Nicolás Cabezudo Rodríguez, "Justicia negociada y nueva reforma procesal penal", Diario La Ley 5815 (2003). 
procesal español". En Reflexiones sobre el nuevo proceso penal: Jornadas sobre el borrador del nuevo Código Procesal Penal, coordinado por Cristina Ruiz López y Raquel López Jiménez, 829-847. Valencia: Tirant lo Blanch, 2015.

-. "Justicia negociada y nueva reforma procesal penal". Diario La Ley, 5.815 (2003).

Conde-Pumpido Ferreiro, Cándido. "El principio de oportunidad reglada: su posible incorporación al sistema del proceso penal español”. En La reforma del proceso penal, 287-308. Madrid: Ministerio de Justicia, 1989.

Córdoba Roda, Juan. "Las conformidades entre acusación y defensa en los procedimientos penales y el problema de la renuncia al derecho". La Ley, n. ${ }^{\circ} 7898$ (2012).

Del Moral García, Antonio. "La conformidad en el proceso penal, reflexiones al hilo de su regulación en el ordenamiento español”, Revista Auctoritas Prudentium 1 (2008). http://www.unis.edu.gt/ap/fetch/conformidad-proceso-penal.pdf

-. "Otra vez sobre la conformidad y conformidades en el proceso penal”, Fernando Herrero Tejedor Algar - Liber Amicorum, dirigido por Antonio Del Moral García y Jaime Moreno Verdejo, 481-508. Madrid: Colex, 2015.

Ferré Olive, Juan Carlos. "El Plea Bargaining, o cómo pervertir la justicia penal a través de un sistema de conformidades low cost”. Revista Electrónica de Ciencia Penal y Criminología 20, no 6 (2018). http://criminet.ugr.es/recpc/20/recpc20-06.pdf.

Gimeno Sendra, Vicente. "El principio de oportunidad y el Ministerio Fiscal”. Diario La Ley 8.746 (2016). 
Gómez Colomer, Juan Luis. "La conformidad, institución clave y tradicional de la justicia negociada en España”. Revue Internationale de Droit Pénal 83 (2012): 15-41.

Hernández García, Javier. "Rapidez y reforma del proceso penal”. Jueces para la Democracia, Información y Debate 44 (2002): 27-32.

Jimeno Bulnes, Mar. “¿Mediación penal y/o justicia restaurativa? Una perspectiva europea y española”. Diario La Ley 8.624 (2015).

Lamadrid Luengas, Miguel Ángel. El principio de oportunidad como una herramienta de política criminal. Barcelona: Universitat Pompeu Fabra, 2015.

Martínez Jiménez, José. Derecho Procesal Penal. Madrid: Tecnos, 2015.

Mateos Rodríguez-Arias, Antonio. "La autonomía del Ministerio Fiscal a la luz de la Constitución”. En Persuadir y razonar: estudios jurídicos en homenaje a José Manuel Maza Martín, coordinado por Carlos Gómez-Jara Díez, 993-1015. Madrid: Aranzadi, 2018,

Velásquez Velásquez, Fernando, La justicia penal: legalidad y oportunidad, Valencia: Tirant lo Blanch, 2018.

Vigil Levi, Jacobo, "La institución de la conformidad en el proceso penal español”, www.julgar.pt/wp-content/uploads/2014/07

Antonio Mateos Rodríguez-Arias Fiscal. Fiscalía provincial de Badajoz Avd. Colón, 8 06005 Badajoz (España) amatrod@unex.es 